\title{
COMMISSION 28: GALAXIES (GALAXIES)
}

\author{
Report of Meetings, 21, 22, 24 and 29 August 1973
}

President: E. M. Burbidge.

ACTING SECRETARY: G. O. Abell.

There were four sessions, of which the first two dealt mainly with business matters, the third (a double session) dealt with residual business matters but was mainly devoted to science, and the fourth mainly to reports from observatories on work in progress.

\section{Business Meeting, 21 August 1973}

G. O. Abell was appointed Acting Secretary, in the absence of M. S. Roberts.

Members stood in silence for one minute in memoriam of M. L. Humason and H. Shapley.

The President noted with regret the resignation from the Commission, and from the Union, of A. R. Sandage.

\section{NEW OFFICERS AND MEMBERS}

The Commission unanimously approved the election by the Organizing Committee of the new President, E. B. Holmberg, and Vice-President, B. E. Markarian. The President proposed and the Commission unarimously approved, the list of names proposed for the new Organizing Committee. The number of Committee members has been increased to provide better coverage both of countries and of topics. It was agreed that the Secretary should be selected by the new President.

Several proposals for new members of the Commission had been received, some from the individuals themselves and others from National Committees. The Organizing Committee had screened the list, and presented the names of those they regarded qualified to the Commission for consideration. Several new names were added by members present. The amended slate was then approved unanimously by the Commission members present.

\section{WORKING GROUPS}

Since the Chairman of the Working Group on Galaxy Photometry and Spectrophotometry, J. L. Sérsic, was unable to be present, G. de Vaucouleurs agreed to chair its meeting. Similarly, Ch. Fehrenbach agreed to replace the Chairman of the Working Group on the Magellanic Clouds, A. D. Thackeray, who could not be present.

P. Pişmiş proposed that a new Working Group on Internal Motions in Galaxies be formed, and agreed to hold an exploratory meeting to see if there was sufficient interest.

\section{COMMISSION RULES}

A discussion was held on the suggestion by the Secretariat that new rules for the organization and conduct of Commissions be formulated and adopted. Since there already exist general rules, contained in the IAU Statutes and By-Laws, the opinion of the Commission was against the formulation of further rules, at least for the present. The members voted unanimously, on a motion of W. G. Tifft seconded by G. de Vaucouleurs, to submit the list of suggestions provided by the Secretariat to the new Organizing Committee for consideration. The Committee would present recommendations, if any, to the Commission at its business meeting during the next General Assembly of the Union. 


\section{Business and Scientific Meeting, 22 August 1973}

\section{REST WAYELENGTHS}

The President put before the Commission a two-part Resolution proposed to Commission 30 . D. S. Heeschen reported that, following discussion by Commissions 30 and 40 , it had been agreed that the first part of the proposed Resolution should be withdrawn. The second part concerned whether to define the rest wavelength, $\lambda_{0}$, used in determining redshifts as the vacuum or air value. The question arises only for large redshifts.

\section{DECISION TAKEN}

It was agreed that, in cases where the difference between vacuum and air values made a significant difference in redshift determinations (e.g. in large redshifts exhibited by narrow absorption lines in quasi-stellar objects (QSOs)) vacuum values of $\lambda_{0}$ should be used.

\section{NOMENCLATURE OF FAINT GALAXIES AND QSOS}

A proposal had been received by V. C. Rubin that, to avoid confusion, a standard nomenclature be adopted for the naming of faint galaxies and QSOs. An ad hoc Working Group of six, consisting of members of Commission 40 as well as Commission 28, was set up under the Chairmanship of J. G. Bolton to consider the matter and formulate a recommendation.

\section{SCIENTIFIC MATTERS}

Since most of the Commission members present had attended the preceding IAU Symposium No 58 in Canberra, on 'The Formation and Dynamics of Galaxies', no summary of this was presented. The meeting concluded with the presentation of two short reports:

W. G. Tifft: On Redshift Uncertainties, Intercomparisons, and the Need for Standards.

G. Burbidge: Description of Lick Observations on a Double QSO, by E. J. Wampler et al.

\section{Scientific and Residual Business Meeting, 24 August 1973}

Prior to the scientific meeting, two residual business matters were settled.

\section{NOMENCLATURE OF FAINT GALAXIES AND OTHER OBJECTS}

J. G. Bolton's ad hoc Working Group presented its recommendation, which was unanimously approved by the Commission as follows:

\section{RECOMMENDATION}

Commission 28 recommends that a co-ordinate numbering system be adopted for all future catalogues of radio sources, X-ray sources, QSOs, galaxies, clusters of galaxies, etc. For general purpose catalogues of the order of $10^{5}$ objects the present 8-digit Parkes system is recommended. The first four digits give the hours and minutes of $\mathbf{R}$. A., the fifth the sign of the declination and the remaining three the degrees and truncated tenths of a degree of declination for the mean equator and equinox of 1950. For special purposes such as occur in dense clusters of galaxies, it is recommended that the eight-digit system be extended as necessary.

\section{REFERENCE FRAME FOR RADIAL VELOCITIES}

Some discussion was held on confusion arising when workers refer radial velocities to different 
standards of rest. It was unanimously agreed that in the future workers should publish observed values of velocity relative to the Sun, and not to the local standard of rest, the galactic centre, or any other reference frame.

\section{SCIENTIFIC PAPERS}

The following short papers or comments were presented.

J. Heidmann: Neutral Hydrogen in Haro Galaxies.

H. E. Bond: Galaxies in the Variable-Star Literature.

W. Wlérick: BL Lacertae.

H. van Woerden: Work at Westerbork on M101, M81, and NGC 3718 (50 cm continuum).

G. Sancisi: Radio Observations of NGC 5383 and NGC 891.

W G. Tifft: A Revision of the NGC.

J. H. Oort: Westerbork Results on NGC 4258.

The scientific session concluded with a discussion of anomalous redshifts. A session of IAU Symposium 58 had been devoted to presentation of the orthodox and unorthodox views, by W. L. W. Sargent and H. C. Arp respectively, and members wished to explore the unorthodox view further. The following short papers were presented:

H. C. Arp: Summary of Observations of Anomalies.

W. G. Tifft: Banded Structures in Redshift-Magnitude Diagram for Clusters.

G. de Vaucouleurs: Virgo Cluster Redshifts.

J.-C. Pecker: New Observational Data, and a Theory of Abnormal Redshifts.

\section{Scientific Meeting, 29 August 1973}

The following reports of work in progress were presented:

G. Alcaino: Extragalactic work at ESO, Chile.

G. de Vaucouleurs: Some Extragalactic Programs at McDonald Observatory.

M.-H. Ulrich: A Complete Sample of Radio Galaxies Identified with Ellipticals.

B. and D. Wills: QSO Spectroscopy at McDonald Observatory.

F. Bertola: Rotation Curves of Early-Type Galaxies.

H. Murdoch: Radio Source Program at Molonglo.

\section{Reports of Working Groups}

G. de Vaucouleurs, C. Fehrenbach and P. Pişmiş submitted the following reports:

\section{GALAXY PHOTOMETRY AND SPECTROPHOTOMETRY}

The group convened on August 28 with G. de Vaucouleurs acting at the request of the Chairman, J. L. Sérsic, who was unable to attend the Sydney Assembly.

\section{ELECTION OF NEW CHAIRMAN $(1973-76)$}

As it has been the practice to rotate the chairmanship of the Group, nominations from the floor were requested. Bertola and de Vaucouleurs declined to be nominated. Dr H. D. Ables, U. S. Naval Observatory, Flagstaff Station, Flagstaff, Arizona was nominated and duly elected unanimously (in absentia) by the 8 members of the group present at the meeting.

Since the WG is open to anyone interested or active in galaxy photometry, no formal election of new members was held; those present not previously on the mailing list will be added automatically.

\section{SCIENTIFIC PAPERS}

G. de Vaucouleurs reviewed recent and current programs in galaxy photometry and spectro- 
photometry at Austin and McDonald Observatory (see report of Commission 28 and of WG). G. Alcaino reported on his program of UBV photometry of 40 southern galaxies of all types selected from Sérsic's Atlas.

A. E. Whitford described progress of his scanner observations of the bulges of M31, M81 (Sb), M33, M51 (Sc) and of the Milky Way. Our Galaxy appears to be a strong-lined Sb spiral.

$M$. Walker presented preliminary results of spectracon observations with the Lick 120 -in. of $3 \mathrm{C} 120$ and NGC6044 showing faint outer extensions of these galaxies.

F. Bertola listed objects under study at Asiago: NGC 128, 3627, 4125, 4258, 4697 for which detailed photometry is in progress.

$J$. Heidmann indicated how combinations of optical and $21-\mathrm{cm}$ parameters can be used to derive extragalactic distances and made a plea for observations of diameters at the 25.0 or 26.5 (B) mag./(arc sec $)^{2}$ levels.

\section{LES NUAGES DE MAGELLAN}

Le groupe a tenu une séance le 28 Août.

1. Le rapport du Dr Thackeray est approuvé mais le complément ci joint (1)-(8) est ajouté; par suite d'une erreur postale, ce rapport est arrivé avec trois mois de retard.

2. Une discussion sur le renouvellement du WG s'engage. M. Westerlund est proposé pour le présider. Les membres de l'ancien groupe pourraient être complétés par Van den Bergh, Reddish, Davies, Toomre, Freeman et Graham. Le nouveau président prendra contact avec le président de la Commission 28 et les membres proposés.

3. Une séance scientifique a lieu où sont données les communications suivantes:

Alcaino: Photometry of globular clusters in MC.

Davies: Magellanic streams.

Fehrenbach: Supergéantes anormales de type A à $F$ dans le GNM.

Nandy: Observation of LMC by the S2/68 sky telescope satellite of ESRO.

Le rapport du Groupe de Marseille-Haute Provence sur les Nuages de Magellan a été retardé plus de trois mois par la poste et le Dr Thackeray m'a demandé d'ajouter exceptionnellement la partie de ce rapport qui n'est pas analysée.

(1) Le catalogue de base de 1970 a été complété par un nouveau catalogue (1972) qui contient 88 étoiles du GNM et 253 étoiles galactiques (Fehrenbach, Duflot). Une troisième liste de 25 étoiles GNM est en préparation.

(2) Une liste de 1832 VR d'étoiles obtenues au P.O. dans la direction du GNM dont 398 étoiles du Nuage est sous presse ( $A$ et $A$ ).

(3) Des études de la rotation (Prévot) et une étude des populations stellaires ont été faites (Brunet) (sous presse $\mathrm{A}$ et $\mathrm{A}$ ).

(4) N. Carozzi a publié en 1971 deux listes d'étoiles à Grande Vitesse dans l'aile du PNM.

(5) Des études de l'absorption dans la direction du GNM ont été publiées (1971, 72, Fehrenbach, Brunet, Prévot).

(6) Des études d'étoiles à GVR galactiques ont été publiées (Fehrenbach, Prévot).

(7) Des études d'astres spéciaux ont été publiées-l'étoile S22 à Fe II (Fehrenbach 1971) dispersion de $20 \AA \mathrm{mm}^{-1}$.

(8) La comparaison des catalogues de Sanduleak et Fehrenbach montre l'existence dans le champ du GNM d'une trentaine d'étoiles A à $F$ à fortes raies d'hydrogène et forte absorption UV.

Sanduleak leur attribue la classe de luminosité II à III. Duflot et Fehrenbach estiment que ce sont des étoiles du GNM de magnitude $-6,2$ à spectre anormal.

\section{REPORT ON THE FORMATION OF A WORKING GROUP ON INTERNAL MOTIONS IN GALAXIES}

Twelve astronomers - six optical and six radio-were present at the meeting scheduled on August 27 under the Chairmanship of P. Pişmiş to discuss the formation of a Working Group on the 
velocity fields in galaxies. It was unanimously agreed that a coordination between the various types of work done on velocity fields was very desirable as it would serve to integrate data obtained by different methods and at different regions of the spectrum; in other words, a collaboration between the radio and optical astronomers working in the field should be carried out in a concerted manner.

It was therefore agreed to form the group under the name of 'Working Group on the Internal Motions of Galaxies' and some discussion was carried out to delineate the functions of the group.

The scope of this Working Group, as far as it is possible to determine at the moment, will be to compile the pertinent velocity data already existing and in the process of being obtained. The WG will recommend or rather appeal to workers in the field to include in their programs certain galaxies in order to attain a complete coverage in all the different regions of the spectrum; these methods might be: absorption-line velocities, $\mathrm{H}$ II region-velocities (spectroscopic, Fabry Perot or by radio recombination lines), $21 \mathrm{~cm} \mathrm{H}_{1}$ line velocities, molecular line velocities, etc.

All those active and interested in this project are invited to membership of the WG. The working group will be coordinated by a Chairman. The first Chairman, unanimously approved by the Commission, will be P. Pişmiş. 